\title{
Compreendendo o Baixo Rendimento Escolar Infantil a partir da Visão Biológica do Desenvolvimento Humano
}

\author{
Alexandre James Ferreira \\ Universidade Católica de Brasília
}

\section{RESUMO}

No âmbito de ensino e aprendizagem, existem diferentes fatores subjacentes ao rendimento escolar, que podem ser abordados sob a perspectiva da teoria bioecológica do desenvolvimento humano. 0 presente trabalho se propõe a compreender o baixo rendimento escolar infantil a partir do modelo bioecológico do desenvolvimento humano de Urie Bronfenbrenner, investigando a aprendizagem de maneira holística, não atendo-se a um único elemento. $O$ estudo aborda a inter-relação entre os ambientes da família e da escola, mostrando que o contexto é um componente estruturante do desenvolvimento e aprendizado da criança, bem como provê um entendimento acerca do baixo rendimento escolar a partir das interações recíprocas entre as características individuais e contextuais.

Palabras clave: teoria bioecológica; baixo rendimento escolar infantil.

\section{RESUMEN}

En el campo de la enseñanza y el aprendizaje, existen diferentes factores subyacentes al rendimiento escolar, que pueden abordarse desde la perspectiva de la teoría bioecológica del desarrollo humano. El presente trabajo tiene como objetivo comprender el bajo rendimiento escolar de los niños a partir del modelo bioecológico del desarrollo humano de Urie Bronfenbrenner, investigando el aprendizaje de manera holística, sin atender a un solo elemento. El estudio aborda la interrelación entre el entorno familiar y el escolar, mostrando que el contexto es un componente estructurante del desarrollo y el aprendizaje del niño, además de proporcionar una comprensión del bajo rendimiento escolar a partir de las interacciones recíprocas entre las características individuales y contextuales. Palavras Clave: teoría bioecológica; bajo rendimiento escolar de los niños.

\begin{abstract}
In the field of teaching and learning, there are different factors underlying school performance, which can be addressed from the perspective of the bioecological theory of human development. The present work aims to understand the low school performance of children from the bioecological model of human development by Urie Bronfenbrenner, investigating learning in a holistic way, not attending to a single element. The study addresses the interrelationship between the family and school environments, showing that the context is a structuring component of the child's development and learning, as well as providing an understanding of low school performance from the reciprocal interactions between individual and contextual characteristics.
\end{abstract}

Keywords: bioecological theory; children low school performance. 


\section{Introdução}

Quais são os fatores envolvidos no baixo rendimento escolar infantil, e como lidar com esse fenômeno? Busca-se difundir o entendimento a respeito destas perguntas através da teoria bioecológica de Urie Bronfenbrenner, e de sua compreensão acerca dos ambientes de desenvolvimento e aprendizado da criança. De acordo com Rodrigues, de Paula e Sá (2014), o modelo bioecológico é marcado por um olhar contextualista, que privilegia, de forma processual, a interrelação das várias camadas de funcionamento do sujeito às demandas de seu contexto. Desta forma, pode-se investigar o andamento do desenvolvimento humano no tocante aos ambientes de aprendizado.

Bronfenbrenner (2001) apresenta sua teoria como sendo uma evolução teórica para o estudo do desenvolvimento humano no decorrer do tempo, entendendo-o como fenômeno de continuidade e mudança nos aspectos biopsicológicos ao longo do ciclo de vida do ser humano, ocorrendo mediante à processos de interações recíprocas, sendo assim bidirecionais.

O desenvolvimento humano trata-se de um processo de constante mudança ao longo da vida do sujeito, que leva em consideração as diversas etapas percorridas por ele no decorrer de sua existência, desde o seu nascimento até a sua morte, não limitando-se a apenas alguns períodos de sua vivência, levando todos em consideração. Tem-se um olhar voltado para as capacidades adaptativas da pessoa, dando atenção não apenas para a mudança do organismo mas também para a de seu contexto, interpretando que este sujeito tem participação ativa em seu desenvolvimento (Benetti, Vieira, Crepaldi, \& Schneider, 2013).

Ao se estudar o desenvolvimento humano, procura-se investigar a mudança e estabilidade de todos os componentes que circundam o desenvolvimento durante o ciclo de vida, sendo eles, os componentes físico, cognitivo e psicossocial, que tem influencia recíproca entre si. Também é levado em consideração o nível socioeconômico e sua consequência, de acordo com a qualidade dos ambientes, lar, vizinhança, nutrição, assistência médica, escolaridade etc., dos quais podem surgir inúmeros fatores que aumentam a chance de efeitos desfavoráveis ao desenvolvimento. Ademais, fatores culturais, étnicos e do momento histórico (Paiva \& Bastos, 2019).

\section{Modelo Bioecológico do Desenvolvimento Humano}

O modelo bioecológico enxerga o desenvolvimento como um processo de inter-relação do sujeito com o ambiente. Para este modelo, o desenvolvimento é regido a partir da atividade que a pessoa exerce em relação ao ambiente, que tipo de estimulação o mesmo oferece à ela, e a constância dessa inter-relação ao longo do tempo (Bruniera, 2016). Bronfenbrenner (2001) ressalta que quando há padrões duradouros de inter-relação no contexto imediato, estes são denominados de processos proximais, e tratam-se da força motriz primária para o desenvolvimento.

A partir de uma visão bioecológica do desenvolvimento, este é concebido como produto e produtor dos processos de interação recíproca, entre o ser humano ativo e os vários contextos nos quais está inserido, devido à isso, é preciso compreendê-lo a partir de uma perspectiva temporal. A pessoa que está em desenvolvimento se modifica ao entrar em contato com um ambiente que lhe oferece oportunidades, da mesma forma que esse ambiente também é modificado por influência da pessoa, evidenciando o caráter bidirecional dessa relação (Marcondes e Sigolo, 2012). O sujeito produz o ambiente que molda o seu desenvolvimento (Papadopoulos, 2018).

A perspectiva bioecológica compreende que um contexto satisfatório de desenvolvimento, resulta da existência e cunho das relações entre os ambientes de convívio do sujeito. Devido a estas associações, a partir deste modelo, o desenvolvimento humano é retratado por meio de quatro núcleos que se relacionam de forma dinâmica, denominados: processo, pessoa, contexto e tempo (Rolfsen e Martinez, 2008). Nesta medida, as contribuições teóricas de Bronfenbrenner, proporcionam uma compreensão multidisciplinar do desenvolvimento humano (Barreto, 2016).

Para entender o desenvolvimento humano, faz-se necessário ter uma visão panorâmica do sistema bioecológico da pessoa, ao passo que ela se desenvolve. No sentido de compreender os elementos desse sistema, é preciso que se tenha uma olhar de ordem simultânea e interdependente acerca de cada um dos componentes do modelo, podendo assim captar suas interligações e relações de funcionamento (Bruniera, 2016).

O conceito de processo refere-se aos processos proximais, ou seja, interações recíprocas e progressivamente mais complexas, que ocorrem durante toda a vida do sujeito conduzindo-a ao desenvolvimento. Para ser eficaz, a interação entre o sujeito e os elementos do ambiente imediato deve ocorrer de forma estável durante longos períodos de tempo. A potência dos processos proximais que geram efeito no desenvolvimento humano, está ligada à aspectos da pessoa em desenvolvimento, o contexto imediato e remoto, e os períodos de tempo em que ele ocorre (Papadopoulos, 2018). Assim como às continuidades e mudanças sociais, e o momento histórico no qual a pessoa vive, atribuindo um caráter oscilatório a seu conteúdo e direção (Schuler, 2015).

A pessoa, trata-se daquele que apresenta atributos biológicos, cognitivos, emocionais e comportamentais em seu repertório idiossincrático, que se manifestam de forma enlaçada. Esses elementos podem ser encarados de duas formas, como desfavoráveis aos processos proximais, tais como disfunções genéticas, deficiências, doenças 
persistentes e processos degenerativos, ou condições que exerçam atividade, fomentando a execução dos processos proximais, como aspectos adquiridos e internalizados pelo sujeito durante o processo de socialização (Papadopoulos, 2018).

Essa linha teórica frisa a importância de se considerar as características individuais da pessoa, tais como seu temperamento, convicções, nível de atividade, metas e motivações, devido a articulação destes com os contextos de seu cotidiano. Esses elementos influenciam a maneira pela qual a pessoa vivencia o ambiente e apontam para que tipo de contextos ela se enquadra. Aspectos pessoais, como gênero e cor de pele, compõe o modo de relacionamento de outros sujeitos com a pessoa em desenvolvimento, demonstrando que valores e expectativas presentes nas relações sociais devem ser levados em consideração (Martins \& Szymanski, 2004).

O contexto refere-se ao meio ambiente em que ocorrem os processos de desenvolvimento, remetendo a ambientes subdivididos que englobam tanto os que a pessoa vive, quanto os que ela nunca esteve, mas que influenciam o seu desenvolvimento (Martins \& Szymanski, 2004). O contexto é entendido no ponto de vista da teoria bioecológica, como uma série de sistemas encaixados, um dentro da outro, separados por quatro níveis: micro-, meso-, exo- e macrossistema. O microssistema é o nível mais interno, tratando-se de atividades padronizadas, papéis e relações interpessoais vivenciadas pelo sujeito em determinado ambiente, com características específicas. O mesossistema trata-se da interconexão entre dois ambientes em que o sujeito participa ativamente. O exossistema diz respeito a interconexão de vínculos do ambiente no qual o sujeito participa ativamente, e ambientes que não participa diretamente, mas que lhe causam influencia. Já o macrossistema, o mais externo, refere-se a ideias, valores, crenças e ideologias que dizem respeito a características do micro, meso e exossistema (Marcondes e Sigolo, 2008). Esses quatro sistemas interconectados formam o contexto no qual o sujeito se desenvolve. Os sistemas podem ser estudados de acordo com suas especificidades, mas é necessário que se observe as relações proeminentes dos demais, devido ao caráter de permeabilidade presente em suas relações (Papadopoulos, 2018).

Para se ter uma melhor compreensão acerca do contexto em relação ao desenvolvimento humano, o ambiente ecológico é entendido como a junção de estruturas homocêntricas, tendo-se como exemplo as bonecas russas, que se encaixam umas nas outras de acordo com os seus tamanhos - da maior (exterior) até a menor (interior) - em referencia ao ambiente mais externo até o mais interno. Levando em conta que esses quatro sistemas rodeiam a pessoa em crescimento (Benetti, Vieira, Crepaldi, \& Schneider, 2013).

Lembrando que estes elementos - processo, pessoa, contexto - são influenciados pelo aspecto temporal, devido ao desenvolvimento ocorrer ao longo do tempo (Papadopoulos, 2018). Sendo este núcleo, a representação do desenvolvimento em seu sentido histórico, que evidencia como se dão as mudanças no desenvolvimento com o passar do tempo, por conta das relações vivenciadas pela pessoa (Martins \& Szymanski, 2004).

\section{Relevância dos ambientes escolares e familiares}

O modelo bioecológico é pertinente para estudos na área de educação ao passo que valoriza o contexto escolar e as inter-relações nele presentes como elementos importantes para o desenvolvimento e aprendizagem ao longo do tempo. Apesar do principal contexto de desenvolvimento da criança ser a família, esta é atravessada pelos outros contextos de seu convívio, presentes em sua cultura e sociedade (Bhering \& Sarkis, 2009). Apesar da imensa influência que a família tem no desenvolvimento infantil, não é adequado endereçala toda a responsabilidade, visto que outros fatores também influem (Guidetti, 2013).

Ao frequentar uma instituição de educação infantil, o que ocorre neste ambiente passa a causar influencia no processo de desenvolvimento da criança. A família e a escola representam dois microssistemas nos quais a criança está inserida, e cada um trará diferentes repercussões para o seu desenvolvimento, porém, o que ocorre em um contexto é levado para o outro e vice-versa. Desta maneira, deve-se levar em consideração a relevância que as interações no âmbito escolar tem para o desenvolvimento (Bhering \& Sarkis, 2009). Apesar dos pais serem as pessoas com as quais as crianças interagem de forma regular e em extensos períodos de tempo, outras pessoas mais velhas, como professores, desempenham papéis importantes nos processos proximais (Martins \& Szymanski, 2004).

Quando a criança adentra o contexto escolar, seus contatos e modo de interação são ampliados, isso gera uma expansão dos processos proximais e por consequência do seu desenvolvimento. De maneira isolada isso já proporciona uma mudança relevante. A entrada da criança nesse contexto pode ocasionar sentimentos ambivalentes nos pais e familiares próximos da criança, trazendo novas preocupações, rotinas e adequações para o microssistema familiar. Devido a esse impacto, a relação entre os microssistemas torna-se uma necessidade (Bhering \& Sarkis, 2009).

Essa interação recíproca entre os ambientes familiares e escolares remetem à importância do potencial transformador que um tem em referência ao outro. Guidetti (2012) afirma que a família é geradora de suporte em relação às atividades escolares, suporte este que se apresenta de forma multifacetada, ao envolver características afetivas, educativas e materiais do vínculo parental. O aspecto afetivo está ligado a dimensão subjetiva, sendo esta os pensamentos e sentimentos manifestados na interação 
com os pais, como por exemplo, receber elogios pelo bom desempenho escolar. Já o aspecto educativo, se trata da organização rotineira da criança, como o estabelecimento de horários para se fazer a lição de casa. Por último, o aspecto material, refere-se aos recursos físicos disponíveis no ambiente familiar, como livros, materiais escolares e espaço para realizar as atividades da escola.

O envolvimento dos pais na educação dos filhos é estabelecido por meio do auxílio direto ou indireto, que as família oferecem as crianças, predominantemente em casa, em referência às atividades escolares. Esse envolvimento pode se manifestar através de diferentes formas, sendo estas, conversas, decisões ou recursos disponíveis ao aprendizado dos filhos (Pestana, 2017).

O vínculo estabelecido entre os microssistemas "família" e "escola" demonstram o caráter integrativo do desenvolvimento, representado pelo mesossistema, no qual é formado o elo entre a família e os amigos da criança, ou a união entre pais e professores na busca de um desenvolvimento sadio da criança. Entretanto, a relação entre microssistemas, exposta através do mesossistema, pode proporcionar interações que são passíveis tanto de promoção quanto de inibição do desenvolvimento (Benetti, Vieira, Crepaldi \& Schneider, 2013).

Acreditava-se que o sucesso escolar era regido pela inteligência do sujeito, as causas para esse sucesso eram buscadas em aspectos restritamente ligados ao aluno: às suas capacidades, motivações e herança genética (Lourenço, 2016). A partir de uma visão bioecológica do desenvolvimento humano, tem-se a compreensão de que o sucesso escolar não é algo que se limita a um fator unicamente intrínseco a pessoa. Percebe-se que o rendimento escolar está vinculado não somente a causas específicas da pessoa, mas também a seu contexto e suas relações. De acordo com Lourenço (2016), o sucesso escolar pode ser concebido como um fenômeno multidimensional que envolve a relação de vários fatores que remetem a experiência das crianças em contínua inter-relação dos sistemas.

O desempenho escolar não é atribuído apenas por experiências do aluno em sala de aula, e na realização das atividades, mas também por diversas características subjetivas (Bruniera, 2016). Quanto maior é o diálogo entre pai e filho, e quanto maior é a implicação dos pais nas atividades escolares, culturais e de lazer da criança, maior é o seu desempenho escolar (Guidetti, 2012). Além do mais, a busca por uma escolarização padronizada, na qual temse a convicção de que se pode educar todos os sujeitos da mesma idade, ao mesmo ritmo e com o mesmo currículo, diz respeito a um caráter ilusório. Quando o aluno não acompanha as aprendizagens curriculares, a chance de se gerar problemas em sala de aula é elevado. A gestão escolar também apresenta-se como fator que compõe a interação contextual, visto que uma boa gestão estimula e molda os seus participantes (Alves, 2014).

O mesossistema torna-se interessante ao apresentar a relação entre os microssistemas. O mesossistema famíliaescola, por exemplo, expressa a sua conexão através da visita dos pais à escola antes da entrada da criança, informações que os pais recebem acerca dos procedimentos escolares, a participação dos pais em atividades em sala de aula com seus filhos, ou seja, todo e qualquer tipo de envolvimento dos pais na vida escolar dos filhos. A relação entre crianças, adultos, e atividades representa o contorno do desenvolvimento humano. As atividades sociais e escolares proporcionam uma interação entre os sujeitos que ocasiona um ambiente propício a processos proximais. Ações articuladas e exercidas por adultos no meio escolar tem elevado impacto no desenvolvimento infantil (Bhering \& Sarkis, 2009).

O papel do professor não se limita a transmissão do conteúdo didático, possibilitando que o mesmo tenha sensibilidade o suficiente para perceber o aluno em seu entorno. A partir desta sensibilidade, o professor é capaz de captar problemas que rodeiam o aluno para além do ambiente escolar, sendo estes, empecilhos que prejudicam o aprendizado e desenvolvimento sadio. Um vínculo positivo estabelecido entre professor e aluno, pode dar confiança para que o aluno busque a ajuda do adulto para lidar com problemas presentes em outros microssistemas (Oliboni, 2008). Isso denota a capacidade de interação entre os microssistemas, sendo um capaz de contrapor a carência do outro, até certo limite. Segundo Bhering e Sarkis (2009), a educação infantil é geradora de impactos sociais pertinentes, que forçam a reestruturação da vida diária familiar.

De acordo com o modelo bioecológico, o aprendizado escolar ocorre predominantemente através da interação dos alunos com as pessoas deste ambiente, sendo também influenciado por outros microssistemas, como a família, pelas características singulares do sujeito e regularidade dos processos proximais ao longo do tempo (Ferreira \& Marturano, 2008). Essa junção, PPCT - processo, pessoa, contexto, tempo - é o que determina o aprendizado segundo uma visão bioecológica do desenvolvimento humano. Marcondes e Sigolo (2008) levantam a possibilidade da inter-relação entre a escola, a família e o aluno, ser o que ocasiona um rendimento escolar negativo, afirmando que o baixo rendimento escolar é um fenômeno que transcorre as relações estabelecidas entre família e escola. Os autores ressaltam que todos os que estão envolvidos direta e indiretamente com o sistema escolar, são afetados por este fenômeno.

Na pesquisa de Marcondes e Sigolo (2008), é apontado que a escola direciona o desempenho inadequado dos alunos à problemas familiares. Ferreira e Barrera (2010), frisam que culpabilizar o aluno e sua família pelo seu baixo rendimento, retirando a responsabilidade da escola, trata- 
se de um movimento ideológico e mistificador, sendo a escola pertencente a este processo. As autoras destacam a importância das variáveis intraescolares, sendo estas: o manejo do professor em sala de aula, quantidade e qualidade do ensino, relação professor-aluno e clima da sala de aula. Do mesmo modo que também apontam a relevância de aspectos extraescolares, referentes ao ambiente familiar, tais como: o envolvimento dos pais na vida escolar da criança e o ambiente educacional no lar. Salientando a família, o aluno e a escola enquanto fatores determinantes para o aprendizado da criança.

Ambientes familiares que possuem livros, jogos e materiais educativos que potencializam as capacidades cognitivas, e contem espaços para que a criança possa estudar, facilitam a aprendizagem escolar. Não retirando a responsabilidade da escola de proporcionar um ambiente lúdico e rico em termos de objetos e componentes culturais, que não dependem dos recursos presentes no ambiente familiar. Todavia, a estrutura não é o suficiente, é necessária a presença dos pais ou de algum adulto que sirva de regulador para administrar e estimular a criança a desfrutar deste ambiente. Sendo o envolvimento ideal dos pais marcado pelo investimento de tempo e de capacidade na criação dos filhos, na medida em que acompanham as atividades escolares, dialogam com a criança e monitoram as suas relações. Estabelecendo um clima emocional positivo, ao fornecer recursos emocionais que indiquem um senso de competência na criança, sendo estes elementos que favorecem o desempenho escolar (Ferreira \& Barrera, 2010).

Os ambientes de maior importância para o desenvolvimento infantil em nossa sociedade tratam-se da família e da escola, nesta medida é fundamental que ocorra comunicação e envolvimento entre ambos para que se proporcione um contexto favorável para o desenvolvimento das crianças (Marcondes \& Sigolo, 2012). No projeto pedagógico escolar deveria ter um espaço dedicado à valorização, reconhecimento e trabalho com os exercício educativos da família, sendo este um recurso relevante nos processos aprendizagem das crianças. Esses exercícios familiares são capazes de gerar um bom rendimento escolar da criança, caso os pais demonstrem interesse pelos conteúdos didáticos. É importante que a criança sinta que o seu aprendizado é valorizado pela família, nesta medida ela é estimulada a exercer as práticas escolares, como frequentar a escola e realizar as lições de casa. Para que a relação entre os microssistemas familiares e escolares seja boa, é preciso que haja dialogo entre os mesmos, fazendoos levar em consideração a relevância um do outro. Os adultos evolvidos, sendo estes os pais e professores, devem estar cientes da necessidade da inter-relação entre esses ambientes (Ferreira \& Barrera, 2010).

Embora a dificuldade de aprendizagem seja ocasionada por diversos fatores internos e externos à criança, ela é mantida pela família, escola e relações sociais do sujeito em desenvolvimento. A maneira com a qual a família e a escola lidam com essa condição, tem um valor decisório na direção e andamento do caso. Não há um perfil típico de uma pessoa com problemas de aprendizagem, os alunos que apresentam essa dificuldade possuem características variadas, voltadas para questões emocionais e sociais (Rolfsen, 2008). É perceptível a heterogeneidade dos fatores presente em grupos de pessoas com dificuldade de aprendizagem, visto que essas características são mantidas pela inter-relação entre os ambientes e a pessoa, e não por aspectos isolados da pessoa ou do contexto.

\section{Papel da criança}

Para lidar com a dificuldade de aprendizado, é necessário que se enxergue as relações através do olhar da criança, como apontam Malagolli, Marcondes e Giraldi (2017), ao afirmarem que quando se escuta a criança, não se acessa apenas a sua particularidade, mas também tem-se contato com a interpretação dos adultos que a circundam. A partir disto, é preciso abdicar da visão hierárquica que se tem do adulto e reconhecer a criança como sujeito ativo, escutando-a para se ter acesso a sua realidade. É indispensável conceber as crianças como sujeitos imersos em uma realidade estruturada por relações emocionais, materiais, sociais e cognitivas, que gerem a sua dinâmica com o mundo. Dessa maneira, as suas identidades são constituídas não através de uma incorporação passiva da cultura exposta pelos adultos, mas de forma ativa, já que digerem essa cultura, dando origem as suas próprias formas de compreensão. Lembrando que esse caráter ativo da criança, ocasiona um fenômeno bidirecional nas relações, expresso por Bronfenbrenner (2001), ao dizer que o desenvolvimento psicológico dos pais é fortemente influenciado pela posição e desenvolvimento de seus filhos.

A criança carrega habilidades que ao serem potencializadas possibilitam o enfrentamento de suas dificuldades escolares. Por isso é necessário dar atenção à sua realidade e trajetória escolar, para ter um melhor entendimento do que está inibindo as suas capacidades. Os sentimentos vivenciados pelas crianças que estão passando por uma situação de baixo rendimento escolar, são os de angústia e tristeza. Sentimentos de medo, vergonha, humilhação e insegurança, correspondem à hostilidade presente em seus contextos (Malagolli, Marcondes, \& Giraldi, 2017).

\section{Conclusão}

É essencial que seja oferecido nas escolas um currículo condizente com as necessidades individuais e coletivas de seus alunos. Ademais, é importante que haja a promoção de um espaço que possibilite a integração com a família, e que a família valorize a vida escolar da criança. Para que se tenha um desenvolvimento integral, é preciso que se tenha 
uma atuação conjunta entre família e escola (Oliveira \& Barbosa, 2015).

Portanto, é preciso incentivar o trabalho simultâneo entre família e escola, proporcionando a aproximação entre esses ambientes educacionais, na busca de objetivos comuns, o aprendizado e desenvolvimento da criança. É inegável a importância do apoio familiar na trajetória escolar dos filhos. Se a escola tomar consciência dessa poderosa influencia, enxergado o potencial colaborativo, ao passo que propicia um ambiente rico em elementos culturais e atividades de ensino e aprendizagem, seguramente haverão melhoras (Ferreira \& Barrera, 2010).

É necessário o contato direto e frequente dos pais com a escola de suas crianças. Os pais deveriam ser informados sobre o que eles podem fazer para auxiliar seus filhos no processo de aprendizagem escolar e a importância de sua participação no que se refere ao desempenho escolar das crianças. Enquanto os pais precisam do auxílio escolar para educar seus filhos, a escola precisa da colaboração dos mesmos para conhecer melhor seu aluno e compartilhar as características deste no ambiente escolar. Além da função dos pais e educadores ser essencial para os processos educativos, de aprendizagem e desenvolvimento da criança, elas podem ser potencializadas caso esses dois microssistemas atuem de forma cooperativa (Guidetti, 2013).

\section{Referências}

Alves, P. C. S. (2014). Os problemas comportamentais associados ao insucesso escolar em escolas da Unidade Orgânica de Rabo de Peixe: estudo de caso. (Tese de Doutorado). Disponível no repositório digital da Universidade Fernando Pessoa.

Barreto, A. C. (2016). Paradigma sistêmico no desenvolvimento humano e familiar: a teoria bioecológica de Urie Brofenbrenner. Psicologia em Revista. 22 (2), 275-293.

Benetti, I. C., Vieira, M. L, Crepaldi, M. A. \& Schneider, D. R. (2013). Fundamentos da teoria bioecológica de Urie Bronfenbrenner. Pensando Psicología, 9(16), 89-99.

Bhering, E., \& Sarkis, A. (2009). Modelo bioecológico do desenvolvimento de Bronfenbrenner: implicações para as pesquisas na area da educação infantil. Horizontes, 27(2), 7-20.

Bronfenbrenner, U. (1a Ed.). (2011). A teoria ecológica do desenvolvimento humano. In Bronfenbrenner, U. Bioecologia do desenvolvimento humano (pp. 43-54). Porto Alegre: Grupo A.

Bruniera, D. S. (2016). A trajetória acadêmica de estudantes universitários diagnosticados com TDAH à luz da Teoria Bioecológica do Desenvolvimento Humano (Dissertação de Mestrado). Disponível na biblioteca digital da Universidade Estadual de Londrina.

Ferreira, S. H. A., \& Barrera, S. D. (2010). Ambiente familiar e aprendizagem escolar em alunos da educação infantile. Psico. 41(4), 462-472.

Ferreira, M. C. T., \& Marturano, E. M. (2008). Recursos da Criança, da Família e da Escola Predizem Competência na Transição da 1a Série. Revista Interamericana de Psicología/Interamerican Journal of Psychology. 42(3), 549-558
Guidetti, A. A. (2013). Desempenho escolar e percepção infantil da motivação e suporte familiar. (tese de doutorado). Disponível na biblioteca digital da UNICAMP.

Lourenço, M. V. (2016). Sucesso escolar, adaptação pessoal, familiar, escolar e social percebidos pelos adolescentes algarvios. (Tese de doutorado). Disponível no repositório digital da Universidade de Huelva.

Malagolli, G. M., Marcondes, K. H. B., \& Giraldi, L. P. B. (2017). Olhares infantis: o baixo desempenho acadêmico, a escola e a família. Revista Brasileira Psicologia Educacional. 19(1), 181-198

Marcondes, K. H. B., \& Sigolo, S. R. (2012). Baixo rendimento escolar e progressão continuada: concepções de alunos, professores e responsáveis. Revista Ibero-Americana de Estudos em Educação. 3(1), 1982-5587.

Martins, E., \& Szymanski, H. (2004). A abordagem ecológica de Urie Bronfenbrenner em estudos com famílias. Estudos e Pesquisas em Psicologia. 4(1), 63-77.

Oliboni, S. P. (2008). O bullying como violência velada: a percepção e a ação dos professores. (Dissertação de Mestrado). Disponível na biblioteca digital da Fundação Universidade Federal do Rio Grande.

Oliveira, A. M., \& Barbosa, A. J. G. (2015). Uma análise bioecológica do baixo desempenho escolar de estudantes com dotação intelectual. Revista Quadrimestral da Associação Brasileira de Psicologia Escolar e Educacional. 19(3), 585-594.

Papadopoulos, C. R. (2018). A trajetória acadêmica de estudantes universitários diagnosticados com TDAH à luz da Teoria Bioecológica do Desenvolvimento Humano. (Tese de Doutorado). Disponível na biblioteca digital da PUC-Rio.

Pestana, J. A. B. (2017). Envolvimento Escolar Parental, Funcionamento Familiar e Comunicação Parento-Filial. (Dissertação de Mestrado). Disponível no repositório digital da Universidade de Madeira.

Paiva, A. F., \& Bastos, C. M. C. (2019). Análise da consideração, nas sentenças, dos depoimentos especiais de crianças, realizados na sala de depoimento acolhedor da capital do Tribunal de Justiça de Pernambuco. (Monografia de especialização). Disponível na biblioteca digital da FACHO.

Rodrigues, A. M., de Paula, M. A. B., \& Sá, M. S. (2014). Diálogos interdisciplinares: olhares, encontros e formação. Revista Ciências Humanas - (UNITAU), 7(2), 1-3.

Rolfsen, A. B. (2008). Elaboração e avaliação de um programa de intervenção psicopedagógico para orientação de pais de crianças com dificuldades de aprendizagem. (Dissertação de Mestrado). Disponível no Repositório Institucional Ufscar.

Rolfsen, A. B., \& Martinez, C. M. S. (2008). Elaboração e avaliação de um programa de intervenção psicopedagógico para orientação de pais de crianças com dificuldades de aprendizagem: um estudo preliminar. Paidéia (Ribeirão Preto), 18(39), 175-188.

Schuler, F. M. G. (2015). "Órfãos da mobilidade": as repercussões da migração da mãe na vida dos filhos que ficaram. (Tese de Doutorado). Disponível na Biblioteca Digital de Teses e Dissertações UCP. 